\title{
Identification of Sri Lankan shrews using hair anatomy
}

\author{
Udeni Menike ${ }^{+}$, Dinushika Manawadu ${ }^{+}$and Suyama Meegaskumbura* \\ Department of Zoology, Faculty of Science, University of Peradeniya, Sri Lanka. \\ ${ }^{+}$Equal contribution \\ Accepted 14 May 2012
}

\begin{abstract}
We report here characteristic features of hair anatomy of all twelve shrew species and subspecies occurring in Sri Lanka. They can be reliably identified using hair anatomy, in most cases by a single characteristic feature. We examined cross-sections, cuticular scale patterns, medulla patterns and made measurements (length and maximal diameter) of dorsal guard hairs ( $\mathrm{GH} 1$ and $\mathrm{GH} 2$ ). We also provide a dichotomous key for identification of shrew species and subspecies based on hair anatomy supported by reference illustrations of cross-sections, photomicrographs of cuticular scales and medullae. Cross-sections of GH2 hairs are characteristic to most species and seven species (Solisorex pearsoni, Feroculus feroculus, Crocidura miya, C. hikmiya, C. horsfieldii, Suncus zeylanicus and S. fellowesgordoni) can be distinguished using cross-sections of $\mathrm{GH} 2$ hairs alone. Cuticular scale patterns are also characteristic to species and subspecies of $S$. murinus, even with variation within species and among hairs of individuals. Medulla pattern is of least importance in shrew species identification, since all have unicellular ladder pattern, but can be used in combination with other characters to distinguish certain species based on whether the ladder pattern is regular or irregular. Hair measurements alone cannot be used in species identification except for $S$. etruscus, which has the shortest guard hairs among the shrews studied.
\end{abstract}

Key words: cuticular scales, guard hair, Sri Lanka, Solisorex, Feroculus, Suncus, Crocidura

\section{INTRODUCTION}

Hair is one of the unique features of mammals. Since the pelage in mammals is an adaptation to life in specific environments, its morphology changes according to the environment in which the animals live. Hence, hair morphology is often unique to a species (Kondo, 2000). Identification of mammalian species using hair morphology was first established with the pioneering work of Hauseman (1920), built upon and promoted by Wildman (1954). With increased use of electron microscopes, scanning electron microscope (SEM) images became a useful technique in hair analysis (Short, 1978; Brazej et al., 1989; Broeck et al., 2000; Meyer, 2002). However, due to limited access to electron microscopes and the high costs involved, many researchers opt to study hair anatomy using optical microscopy.

Identification of mammal species using hair anatomy has many applications, especially in taxonomy (Mayer, 1952; Marinis and Asprea, 2006a; Cavia et al., 2008; Teerink, 1991). Analysis of prey hair found in feaces or pellets is used as a non-destructive method of studying food habits of carnivores (Brunner and Coman, 1974; Perrin and Campbell, 1980; Amerasinghe and Ekanayake, 1990; Henscel et al., 2005). Hair samples collected using hair tubes is also widely used to study population distributions, microhabitat utilization and food habits of mammals (Day, 1966; Spaulding et al., 2000). Forensic medicine (Hausman, 1934; Rosen, 1974; Birngruber, 2009), paleontology (Vullo et al., 2010), and anthropology (Backwell et al., 2009) are other fields where mammal hair anatomy is used in various ways.

The pelage of most mammals consists of more than one type of hair. There are two main types recognized, guard hair or overhair and underhair of which, only guard hairs are of taxonomic importance (Teerink, 1991). Guard hairs are long and stiff with two prominent parts, a thinner proximal or basal part (shaft) and denser distal or apical part (shield). Guard hair can be easily distinguished from underhair, which are slender and undulating (Teerink, 1991). There are three types of guard hairs (GH0, GH1 and GH2), of which GH1 and GH2 are the most widely used in anatomical studies. GH1 hairs are usually straight and stiff while $\mathrm{GH} 2$ hairs are bent at the juncture of shaft and shield (Teerink, 1991). Two main structural components, the cuticular scale patterns and the medullar patterns are studied in detail for

*Corresponding author's email: suyamam@pdn.ac.lk 
distinguishing species (Fernandez and Rossi, 1998; Mayer et al, 2000; Marinis and Asprea, 2006b). In addition, cross-sections, length and maximal diameter of hair, and hair profile are used in distinguishing species (Teerink, 1991; Cavia, 2008).

Shrews have an important and a unique place among the Sri Lankan mammalian fauna. There are ten species belonging to four genera with one genus and five other species endemic to the island (Hutterr, 2005; Meegaskumbura et al., 2007; Meegaskumbura and Schneider, 2008; Meegaskumbura et al., 2012). Though geographic subspecies are not recognized by many authors, we included subspecies of $S$. murinus in the study as they are morphologically distinct (Phillips, 1980; Meegaskumbura et al., 2010).

A single study carried out on hair anatomy of mammals of Sri Lanka (Amerasinghe, 1983) provides a dichotomous key for most of the mammal species in the island. For shrews, however, the study includes only an identification key for the four Sri Lankan genera.
Nevertheless, detailed images or photographs and descriptions in addition to taxonomic keys for correct identification of species are important (Teerink, 2001). Hence, we characterized hairs of all the twelve Sri Lankan shrew species and subspecies, providing photomicrographs of cuticular scales and medullae, together with illustrations of cross-sections.

\section{MATERIALS AND METHODS}

Hair samples of shrew species and subspecies collected during an islandwide small mammal survey conducted by the last author (SM) from 2003 to 2005 were used in the present study, except that of Suncus zeylanicus, which was obtained from the Natural History Museum (NHM), London (Table 1). Voucher specimens of collected shrews originally deposited in the collection of the Wildlife Heritage Trust (WHT) are now placed in the Department of Zoology, University of Peradeniya, Sri Lanka.

Table 1. List of shrew species and subspecies examined for hair anatomy.

(WHT - Wildlife Heritage Trust; BMNH - British Museum of Natural History)

\begin{tabular}{|c|c|c|}
\hline Species & Collection site & $\begin{array}{l}\text { Voucher specimen } \\
\text { reference number }\end{array}$ \\
\hline *Solisorex pearsoni (Person's Long-clawed Shrew) & Agarapathana & WHT 6824, WHT 6811 \\
\hline Feroculus feroculus (Kelaart's Long-clawed Shrew) & Horton Plains & WHT 6811 \\
\hline *Crocidura miya (Ceylon Long-tailed Shrew) & Agarapathana & WHT 6826, WHT 6895 \\
\hline${ }^{*}$ C. hikmiya (Sinharaja Shrew) & Sinharaja & WHT 6836, WHT 6849 \\
\hline C. horsfieldii (Horsfield's Shrew) & Peradeniya & WHT 6869, WHT 6872 \\
\hline Suncus etruscus (Etruscan Shrew) & Anuradhapura & WHT 6936 \\
\hline *S. fellowesgordoni (Ceylon pigmy Shrew) & Agarapathana & WHT 6818 \\
\hline *S. zeylanicus (The Ceylon Jungle Shrew) & Kitulgala & BMNH 1928.1.25.1 \\
\hline *S. montanus (The Ceylon Highland Shrew) & Agarapathana & $\begin{array}{l}\text { WHT } 6815 \text {, WHT } 6822 \text {, } \\
\text { WHT } 6860\end{array}$ \\
\hline S. murinus murinus (The common Indian Musk- Shrew) & Anuradhapura & WHT 6907, WHT 6906 \\
\hline S. m. kandianus (The Kandyan Shrew) & Peradeniya & WHT 6874 \\
\hline S. m. caerulescens (The Indian Grey Musk-Shrew) & Colombo & WHT 6881 \\
\hline
\end{tabular}

* Endemic species 
Dorsal hair samples from one to three individuals from each species and subspecies were used in the study. Only GH1 and GH2 hairs from the dorsal surface of shrews were considered, since they show the most characteristic features.

Cross-sections of only $\mathrm{GH} 2$ hairs were considered, since the cross-sections of GH1 hairs are circular in all shrew species studied. Crosssections of hairs were taken using botanical pith (Amerasinghe, 1983). One hair at a time was adhered to strips of pith parallel to the longitudinal axis using clear nail polish and thin cross sections were taken by cutting with a clean, sharp razor blade. The series of cross sections mounted on glass slides were observed under the microscope. Five GH2 hairs from each individual were used for cross-sectioning.

Cuticular scale patterns of both GH1 and GH2 were observed using scale casts on a thin layer of clear nail polish. The cuticular patterns vary to some extent within a species and among hairs of an individual. We have included the most common pattern for a species in Fig. 1, from a minimum of five $\mathrm{GH} 1$ and $\mathrm{GH} 2$ hairs from each species.

Medullar patterns of $\mathrm{GH} 2$ hairs were observed using five hairs from each individual, mounted in DPX on microscopic glass slides. Photomicrographs of all cross-sections, cuticular scale casts and medullae were taken using a USB camera connected to a light microscope. Length and maximal diameter of five $\mathrm{GH} 1$ and five $\mathrm{GH} 2$ hairs from each individual were taken using scaled photomicrographs in ImageJ computer software. A dichotomous key was constructed to identify hairs at species and subspecies level. Nomenclature of hair anatomy follows Teerink (1991).

\section{RESULTS}

\section{Cross-Sections of GH2 hairs}

Cross-sections along the shield of $\mathrm{GH} 2$ hairs differed markedly among species of shrews and are important for differentiating them (Table 2). Seven species can be easily distinguished using cross-sections of $\mathrm{GH} 2$ hairs alone. They are Solisorex pearsoni: cross-sections circular or oval with a flattened or concave side; Feroculus feroculus: cross-sections with two deep emarginations; Crocidura miya: X-shaped crosssections; C. hikmiya: butterfly-wing shaped, large $(51.2-104.8 \mu \mathrm{m}) \quad$ cross-sections with characteristic teardrop-shaped medulla; $C$. horsfieldii: four-petaled flower shaped cross- sections; Suncus zeylanicus: square-shaped cross-sections and S. fellowesgordoni: H-shaped cross-sections. Of the other species, S. etruscus has similar shaped cross-sections to $S$. fellowesgordonii but $\mathrm{H}$-shaped cross sections are not very apparent in the former species (Table 2). Cross-sections of $S$. etruscus hairs are smaller in size than those of $S$. fellowesgordoni, hence can be distinguished from $S$. fellowesgordonii. Cross-sections of $S$. montanus and the three subspecies of $S$. murinus are similar in shape and size (Table 2), hence cannot be used for identification. Cross-sections along the shaft of $\mathrm{GH} 2$ hairs in all the shrew species studied are circular.

\section{Cuticular scale patterns of GH1 and GH2 hairs}

Cuticular scale patterns of both $\mathrm{GH} 1$ and $\mathrm{GH} 2$ hairs are characteristic to species and subspecies and can be used in identification. Of the GH1 hairs, only $C$. hikmiya, $S$. etruscus and $S$. fellowesgordoni have streaked shields while the others have irregular waved scale patterns. Depending on the species, these irregular-wave patterns can be rippled or smooth, or become rippled towards the tip of the hair (Fig. 1). Shafts of GH1 hair have broad or elongated petal scales in $S$. pearsoni, $F$. feroculus, $C$. miya, $S$. zeylanicus, S. montanus, $S . \quad m$. kandianus; diamond shaped petal scales in $C$. horsfieldii, $S$. fellowesgordoni, C. miya and mosaic scales in $C$. hikmiya, S. horsfieldii, S. murinus murinus, S. m. caerulescens. Certain species have more than one scale pattern in the shaft (Fig. 1).

$\mathrm{GH} 2$ hairs of all species except Solisorex pearsoni, Feroculus feroculus and Suncus zeylanicus have streaked shields. Shields of $S$. pearsoni, F. feroculus and S. zeylanicus have smooth irregular wave scale patterns while hairs of $S$. zeylanicus have regular wave pattern towards the tip. Except $C$. horsfieldii, S. etruscus and $S$. fellowesgordoni, all the other species have elongated or broad petals in the shaft. Crocidura horsfieldii, S. etruscus and S. fellowesgordoni have diamond-shaped petals (Fig. 1 and Table 3). Crocidura hikmiya has mosaic scales between the streaked and petal scales, while $C$. miya, S. zeylanicus, $S$. montanus and $S . m$. kandianus have diamond shaped petals in between.

Though the cuticular scale patterns can be broadly categorized as above, the shapes and sizes of scales, and the extent of each pattern that spreads along the length of the hairs are characteristic to each species (Fig. 1). 
Table 2. Cross-sections of the shield in GH2 hairs of shrew species and subspecies in Sri Lanka.

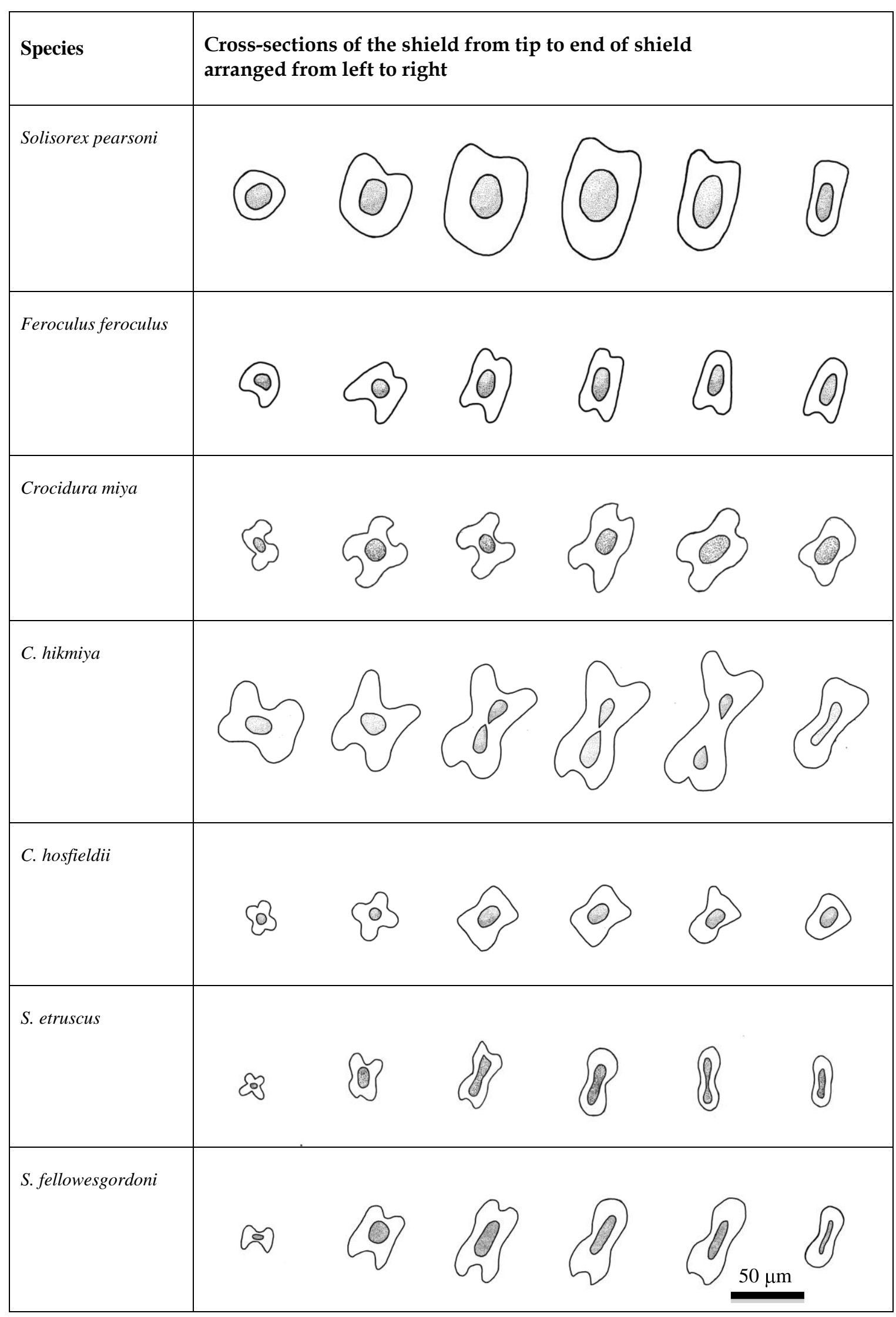




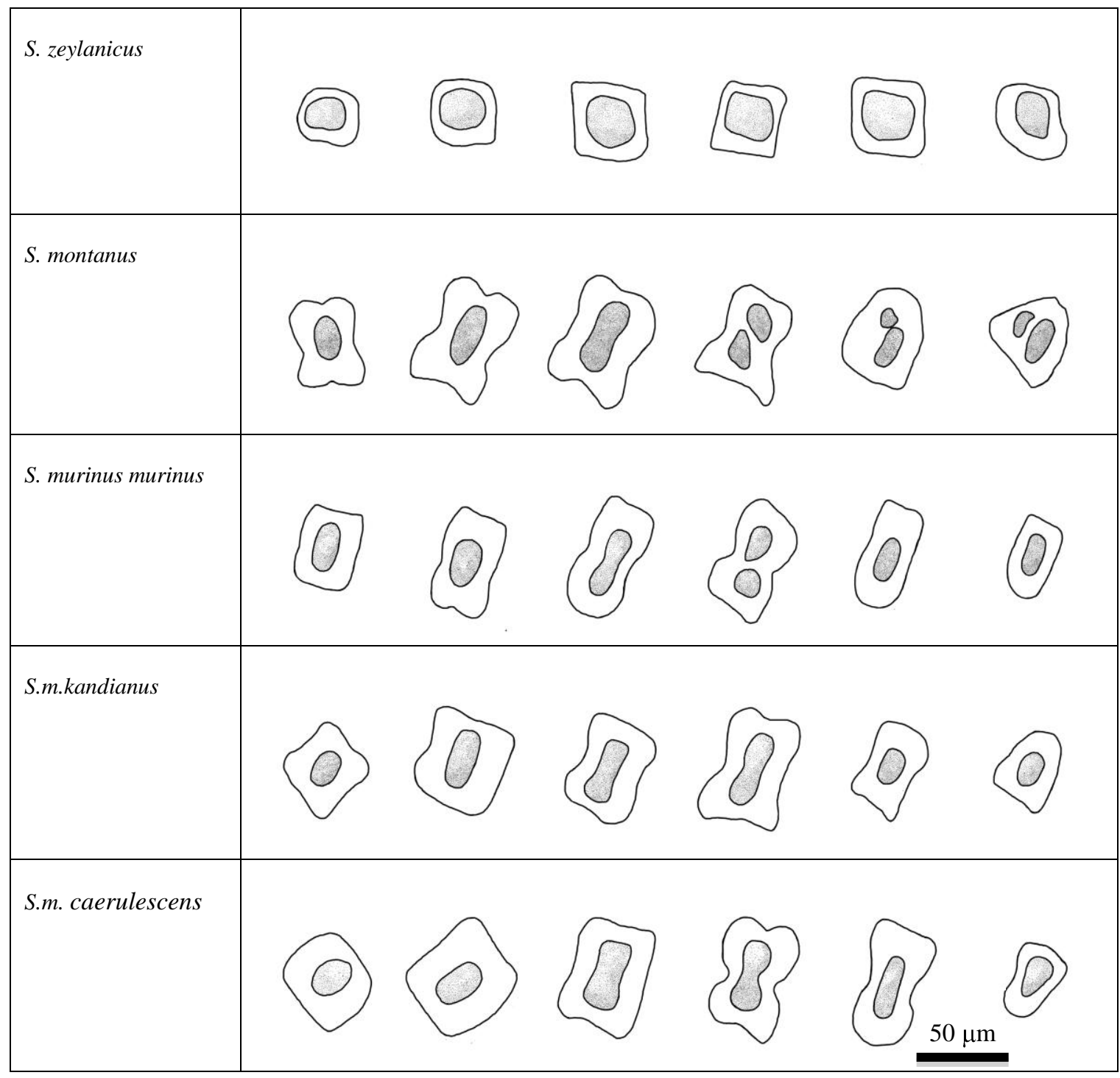

\section{Length and maximal diameter of GH1 and GH2 hairs}

Length and maximal diameter of hairs cannot be solely used in identification of species but can be used in combination with other features. One exception is, S. etruscus, which has the shortest hair (GH1: $1.0-1.2 \mathrm{~mm}$ and $\mathrm{GH} 2$ : $0.9-1.0 \mathrm{~mm}$; Table 4) among the shrews species studied.

\section{Medulla patterns of GH2 hairs}

The medulla pattern of $\mathrm{GH} 2$ hairs is not informative for differentiating the species of shrews as all have a unicellular ladder pattern with scalloped margins. Two species, however, have an irregular ladder pattern (Crocidura hikmiya and $S$. $m$. caerulescens) while the rest have a regular ladder pattern (Fig. 2). Suncus etruscus can be distinguished from others by the characteristic appearance of the medulla ladder pattern (Fig. 2f). Suncus $m$. murinus has a regular ladder pattern, but occasionally shows a region with an irregular ladder pattern (Fig. 2j) 
Table 3. Comparison of cuticular scale patterns of GH1 and GH2 hairs of shrew species and subspecies of Sri Lanka.

\begin{tabular}{|c|c|c|}
\hline Species & GH1 & GH2 \\
\hline Solisorex pearsoni & $\begin{array}{l}\text { irregular wave (distant to close, } \\
\text { smooth to rippled) } \\
\text { broad/ elongate petal (smooth) }\end{array}$ & $\begin{array}{l}\text { irregular wave (distant to close, } \\
\text { smooth to rippled) } \\
\text { broad/ elongate petal (smooth) }\end{array}$ \\
\hline Feroculus feroculus & $\begin{array}{l}\text { irregular wave (distant Smooth to close } \\
\text { rippled) } \\
\text { broad petal (smooth) }\end{array}$ & $\begin{array}{l}\text { irregular wave (distant smooth to close } \\
\text { rippled) } \\
\text { broad petal (smooth) }\end{array}$ \\
\hline Crocidura miya & $\begin{array}{l}\text { irregular wave (distant smooth to } \\
\text { rippled near) } \\
\text { elongate to diamond shaped to broad } \\
\text { petal (smooth) }\end{array}$ & $\begin{array}{l}\text { streaked (distant to close smooth to } \\
\text { rippled) } \\
\text { elongate to diamond shaped to broad } \\
\text { petal (smooth) }\end{array}$ \\
\hline C. hikmiya & $\begin{array}{l}\text { streaked (distant to near to close } \\
\text { smooth) } \\
\text { mosaic (distant Smooth) }\end{array}$ & $\begin{array}{l}\text { streaked (distant to close smooth to } \\
\text { rippled) } \\
\text { mosaic (distant smooth) } \\
\text { elongate to broad petal (smooth) }\end{array}$ \\
\hline C. horsfieldii & $\begin{array}{l}\text { irregular wave (near rippled) } \\
\text { mosaic (distant smooth) } \\
\text { diamond shaped petal (smooth) }\end{array}$ & $\begin{array}{l}\text { streaked (distant to close smooth to } \\
\text { rippled) } \\
\text { diamond shaped petal (smooth) }\end{array}$ \\
\hline Suncus etruscus & $\begin{array}{l}\text { streaked (distant to close smooth to } \\
\text { rippled) } \\
\text { elongate to broad petal (smooth) }\end{array}$ & $\begin{array}{l}\text { streaked (distant to close smooth to } \\
\text { rippled) } \\
\text { diamond shaped petal (smooth broad) }\end{array}$ \\
\hline S. fellowesgordoni & $\begin{array}{l}\text { streaked (distant to near smooth) } \\
\text { diamond shaped petal (smooth broad) }\end{array}$ & $\begin{array}{l}\text { streaked (distant to near smooth) } \\
\text { diamond shaped petal (smooth broad) }\end{array}$ \\
\hline S. zeylanicus & $\begin{array}{l}\text { irregular wave (close to near smooth) } \\
\text { elongate to broad petal (smooth) }\end{array}$ & $\begin{array}{l}\text { regular wave (close to near smooth) } \\
\text { irregular wave (distant to close } \\
\text { smooth) } \\
\text { elongate to diamond shaped to broad } \\
\text { petal (smooth) }\end{array}$ \\
\hline S. montanus & $\begin{array}{l}\text { irregular wave (distant to near smooth) } \\
\text { elongate petal (smooth) }\end{array}$ & $\begin{array}{l}\text { streaked (distant to near smooth to } \\
\text { rippled) } \\
\text { elongate to diamond shaped petal } \\
\text { (smooth) }\end{array}$ \\
\hline S. murinus murinus & $\begin{array}{l}\text { irregular wave (close to near rippled) } \\
\text { mosaic (distant smooth) }\end{array}$ & $\begin{array}{l}\text { streaked (distant to near smooth to } \\
\text { rippled) } \\
\text { elongate / broad petal (smooth) }\end{array}$ \\
\hline S. m. kandianus & $\begin{array}{l}\text { irregular wave (distant to close rippled) } \\
\text { elongate to broad petal (Smooth) }\end{array}$ & $\begin{array}{l}\text { streaked (distant to near smooth to } \\
\text { rippled) } \\
\text { elongate to diamond shaped petal } \\
\text { (smooth) }\end{array}$ \\
\hline S. m. caerulescens & $\begin{array}{l}\text { irregular wave (close to near rippled) } \\
\text { mosaic (distant Smooth) }\end{array}$ & $\begin{array}{l}\text { streaked (distant to near smooth to } \\
\text { rippled) } \\
\text { elongate to broad petal (smooth) }\end{array}$ \\
\hline
\end{tabular}



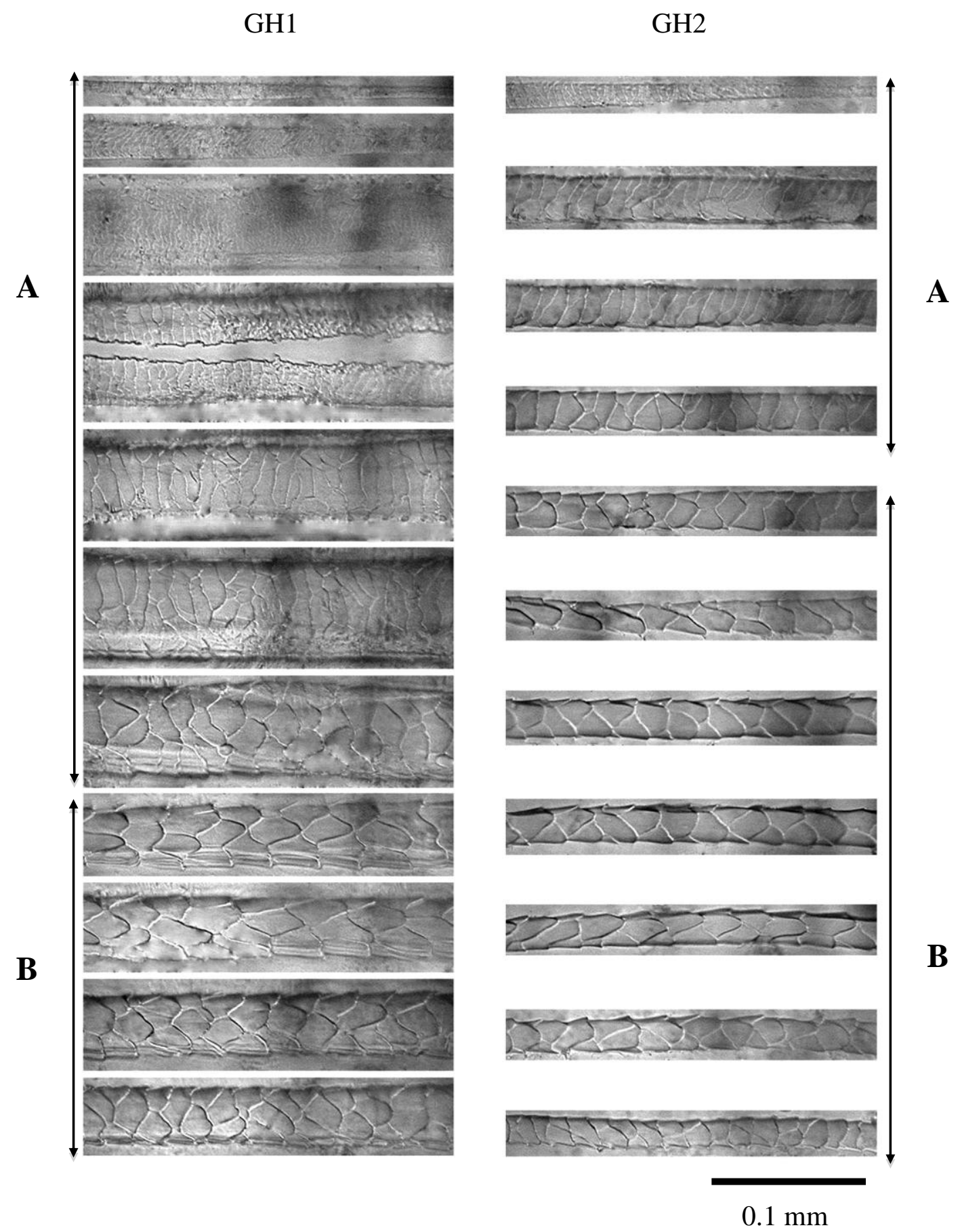

A. GH1/ GH2 - irregular wave (distant to close, smooth to rippled)

B. GH1 / GH2 - broad/ elongate petal (smooth)

Figure 1a. Photomicrographs of cuticular scale patterns of GH1 and GH2 hairs of Solisorex perasoni. (Scales from tip to base of hairs - arranged from top to bottom) 
GH1

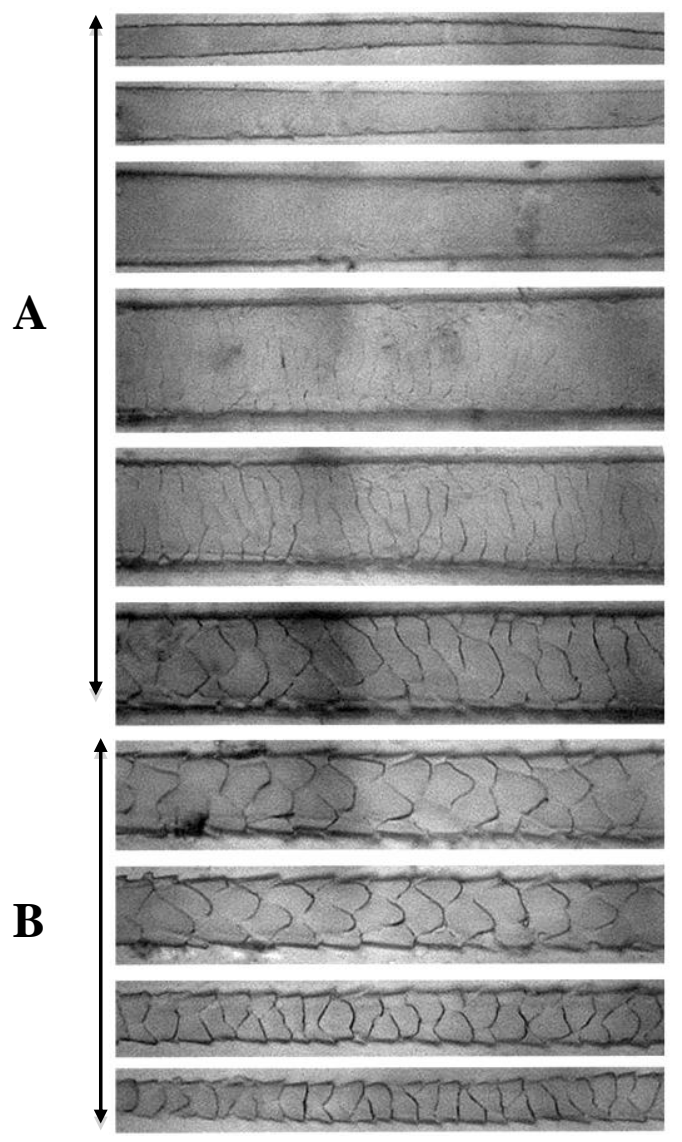

$\mathrm{GH} 2$
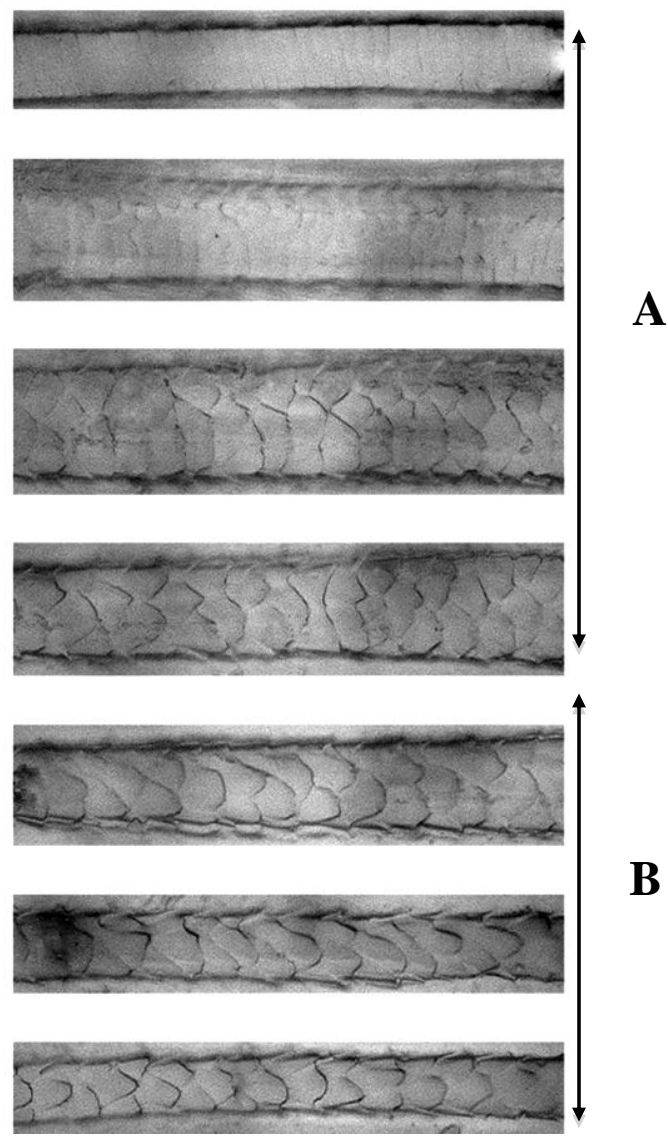

B

$0.1 \mathrm{~mm}$

A. GH1/ GH2 - Irregular wave (distant smooth to close rippled)

B. GH1/ GH2 - broad petal (smooth)

Figure 1b. Photomicrographs of cuticular scale patterns of GH1 and GH2 hairs of Feroculus feroculus. (Scales from tip to base of hairs - arranged from top to bottom) 
GH1

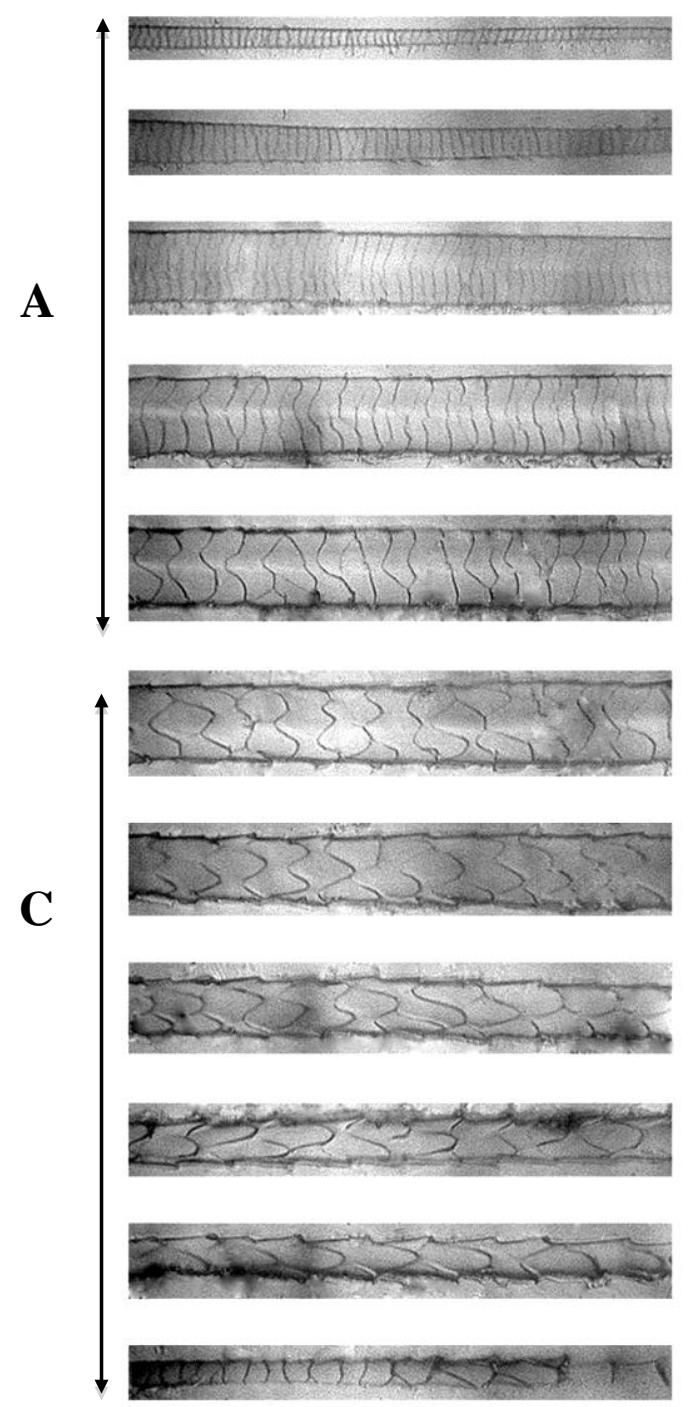

$\mathrm{GH} 2$
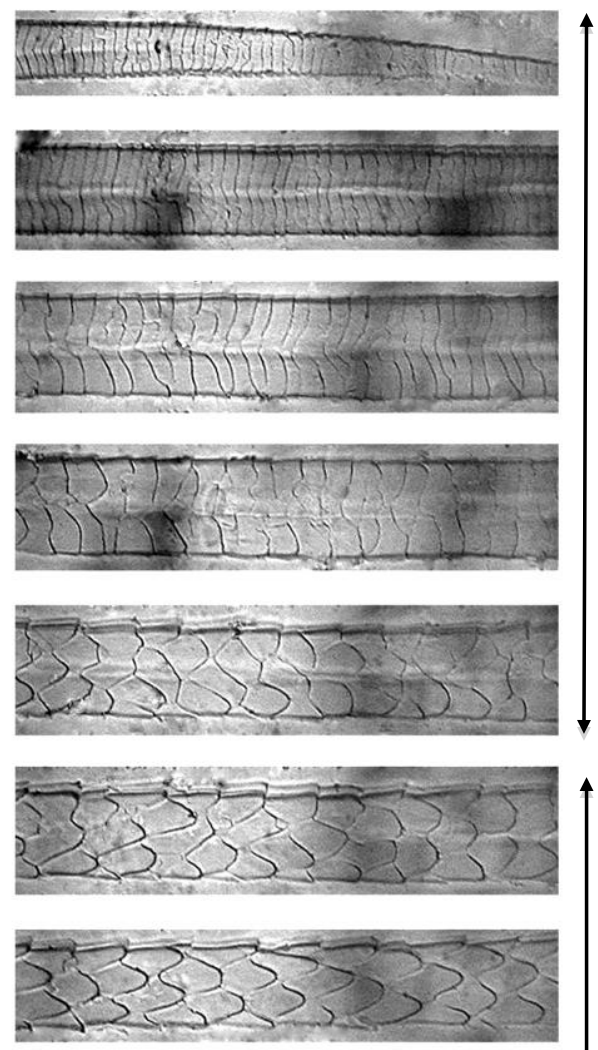

C
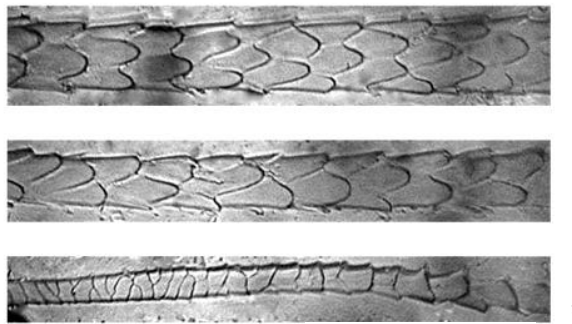

$0.1 \mathrm{~mm}$

A. GH1 - irregular wave (distant smooth to rippled near)

B. GH2 - streaked (distant to near to close, smooth to rippled)

C. GH1/GH2- elongate to diamond shaped to broad petal (smooth)

Figure 1c. Photomicrographs of cuticular scale patterns of GH1 and GH2 hairs of Crocidura miya. (Scales from tip to base of hairs - arranged from top to bottom) 
GH1

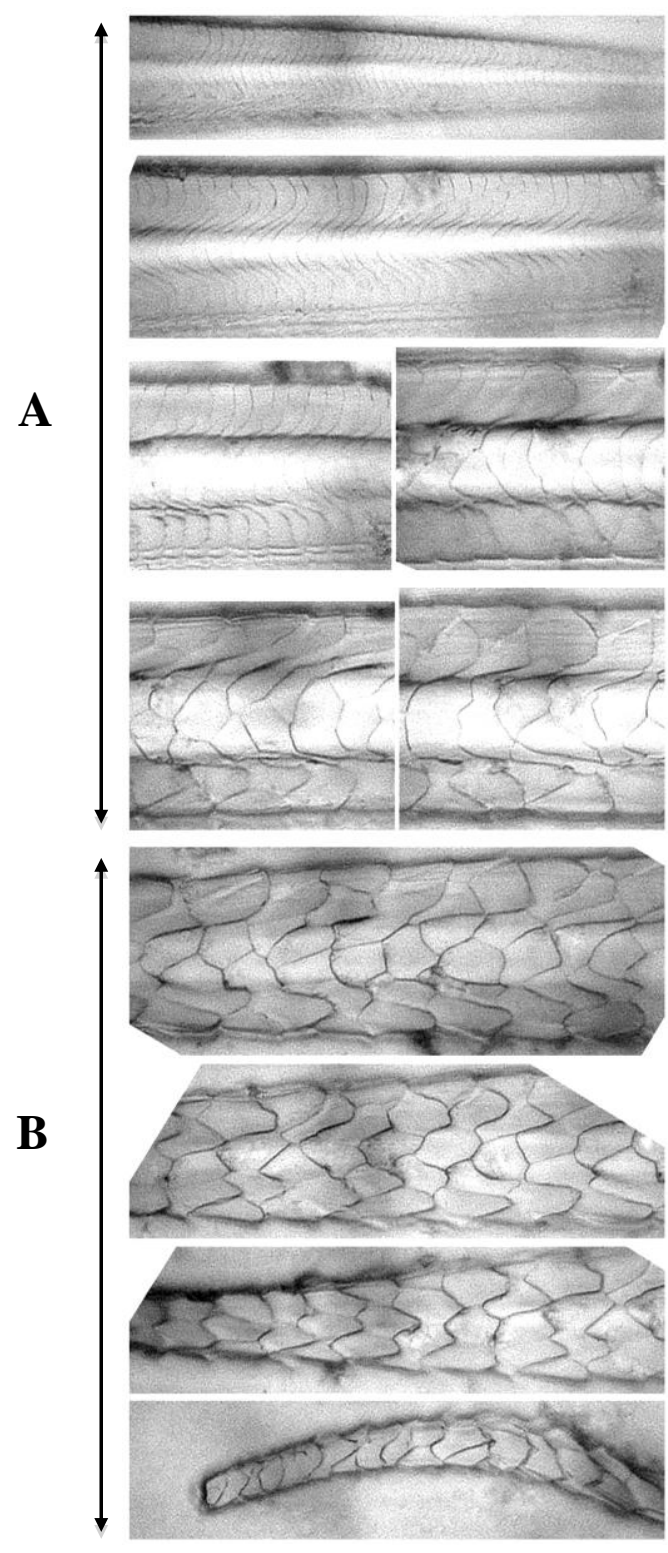

$\mathrm{GH} 2$

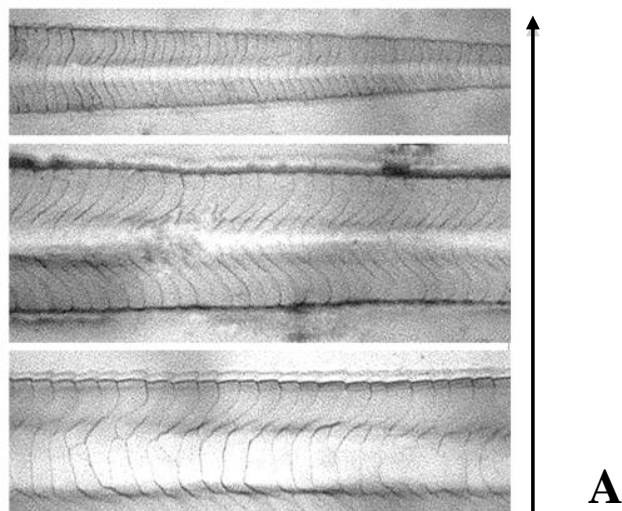

A

B

C

A. GH1/ GH2 - streaked (distant to close smooth)

B. GH1/ GH2- mosaic (distant smooth)

C. GH2 - elongate petal (smooth)

Figure 1d. Photomicrographs of cuticular scale patterns of GH1 and GH2 hairs of Crocidura hikmiya. (Scales from tip to base of hairs - arranged from top to bottom) 
GH1

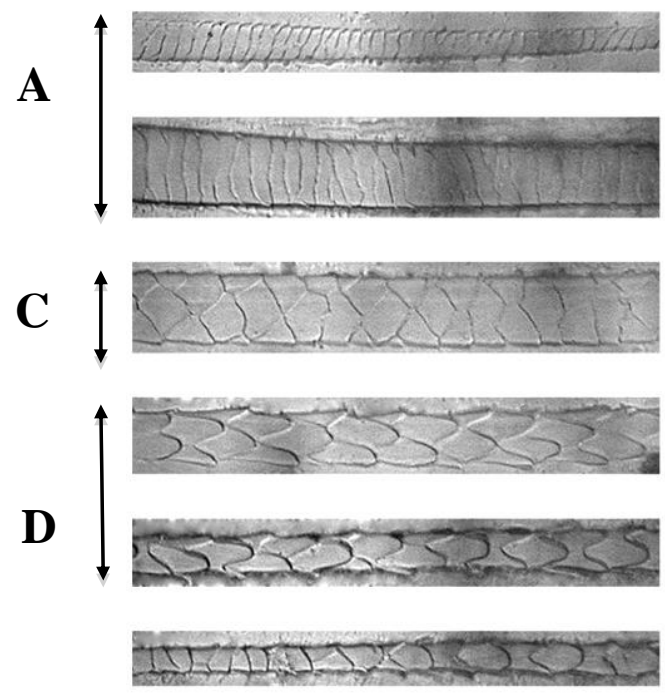

GH2
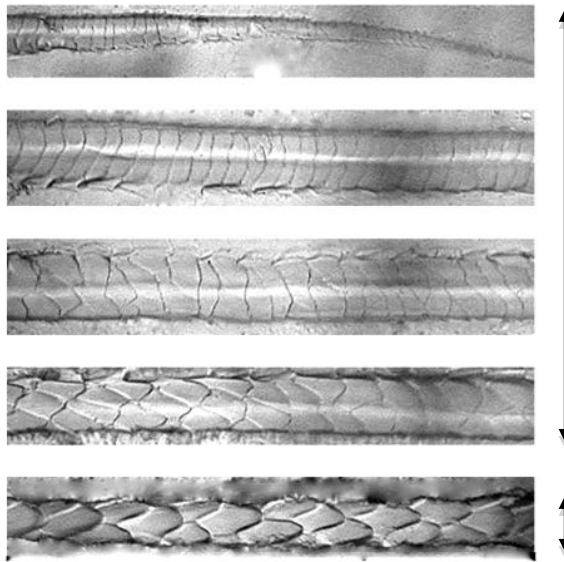

D

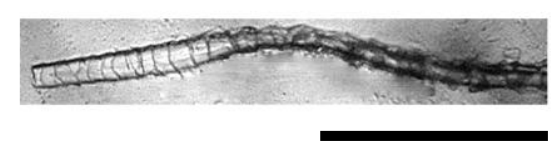

$0.1 \mathrm{~mm}$

B$$
\text { D }
$$

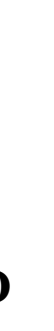


GH1

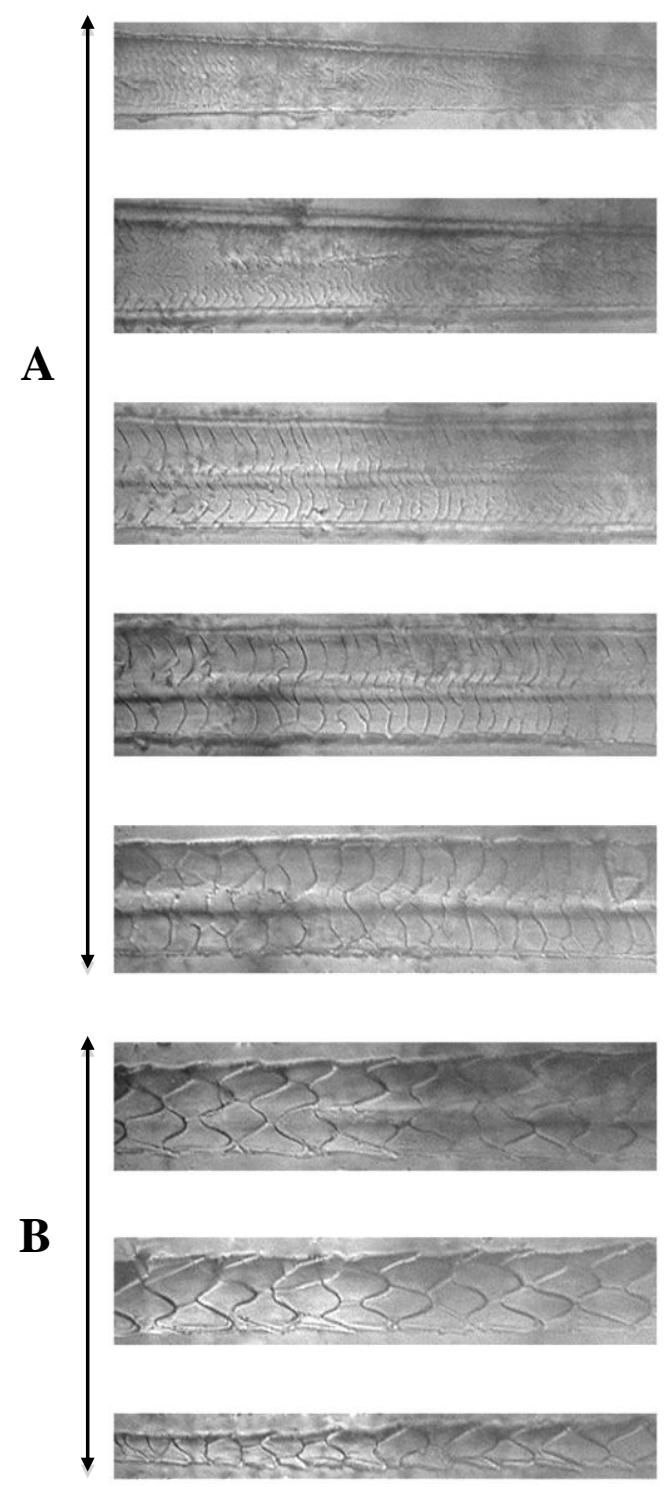

$\mathrm{GH} 2$
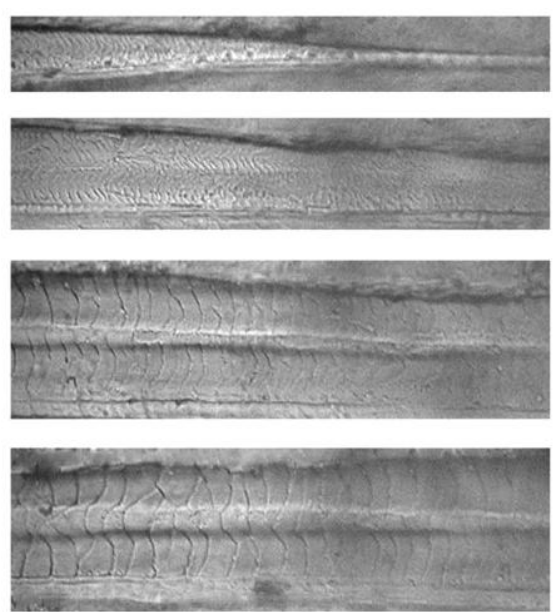

A
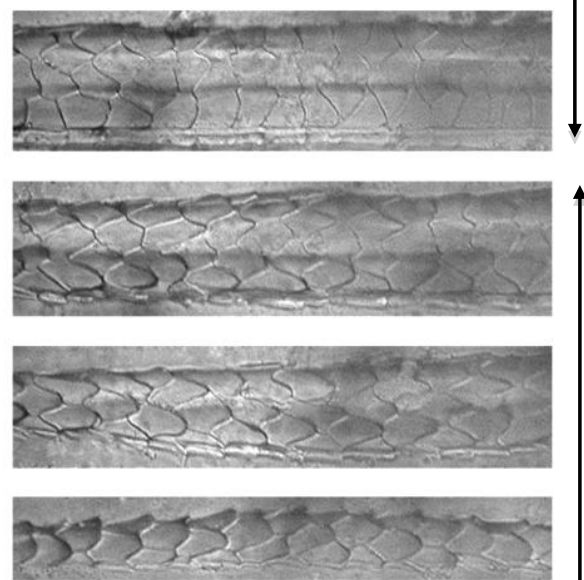

B

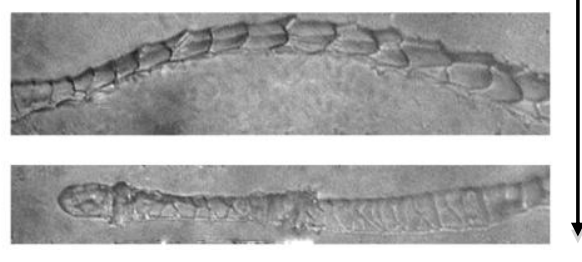

$0.1 \mathrm{~mm}$
A. GH1/ GH2 - streaked (distant to near smooth)
B. GH1/ GH2 - diamond shaped petal (smooth broad)

Figure 1g. Photomicrographs of cuticular scale patterns of GH1 and GH2 hairs of Suncus fellowesgordoni. (Scales from tip to base of hairs - arranged from top to bottom) 
GH1

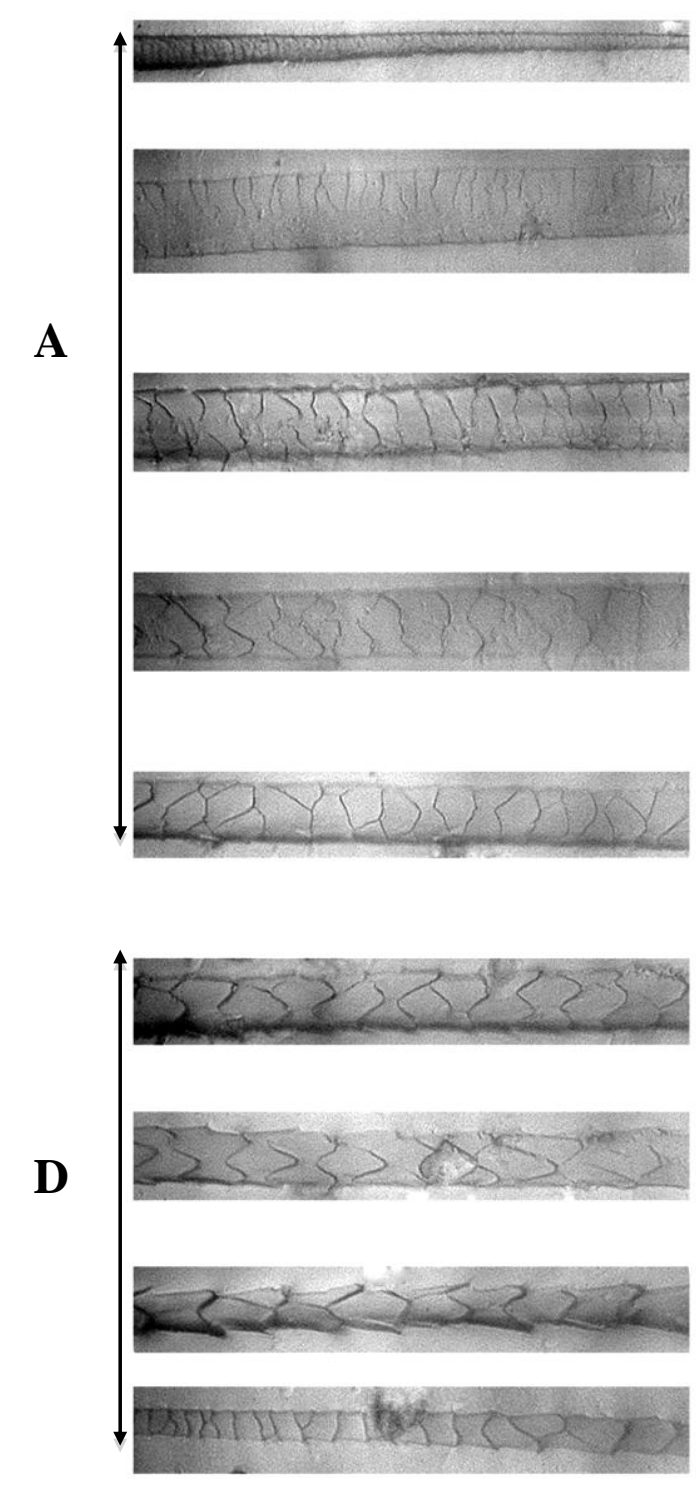

$\mathrm{GH} 2$
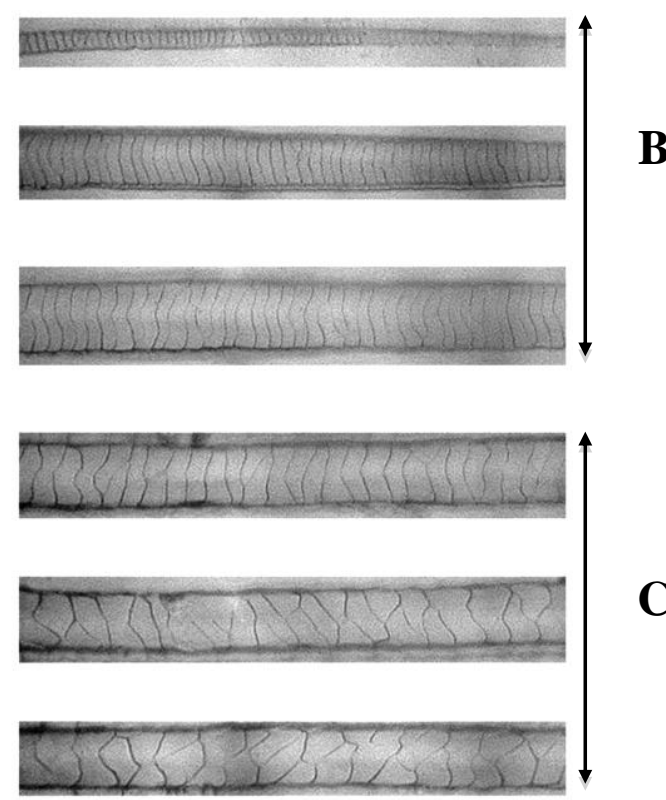

C

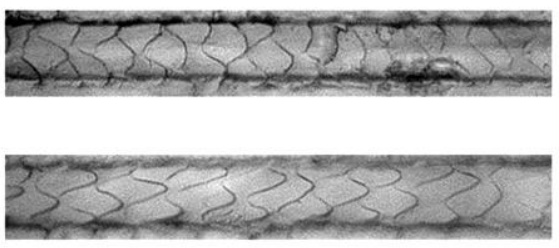

$\mathbf{E}$
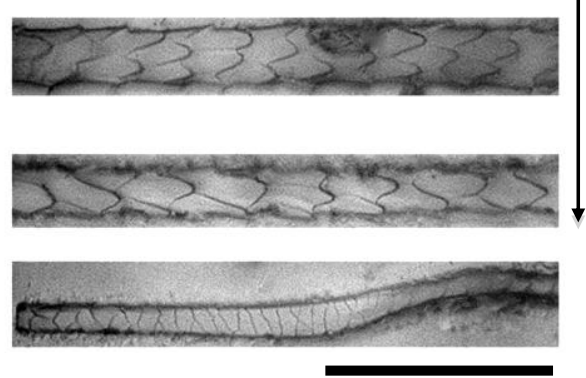

$0.1 \mathrm{~mm}$

B
A. GH1 - irregular wave (close to near smooth)
B. GH2 - regular wave (close to near smooth)
C. GH2 - irregular wave (distant to close smooth)
D. GH1 - elongate to broad petal (smooth)
E. $\mathrm{GH} 2$ - elongate to diamond shaped to broad petal (smooth)

Figure 1h. Photomicrographs of cuticular scale patterns of GH1 and GH2 hairs of Suncus zeylanicus. (Scales from tip to base of hairs - arranged from top to bottom) 
GH1

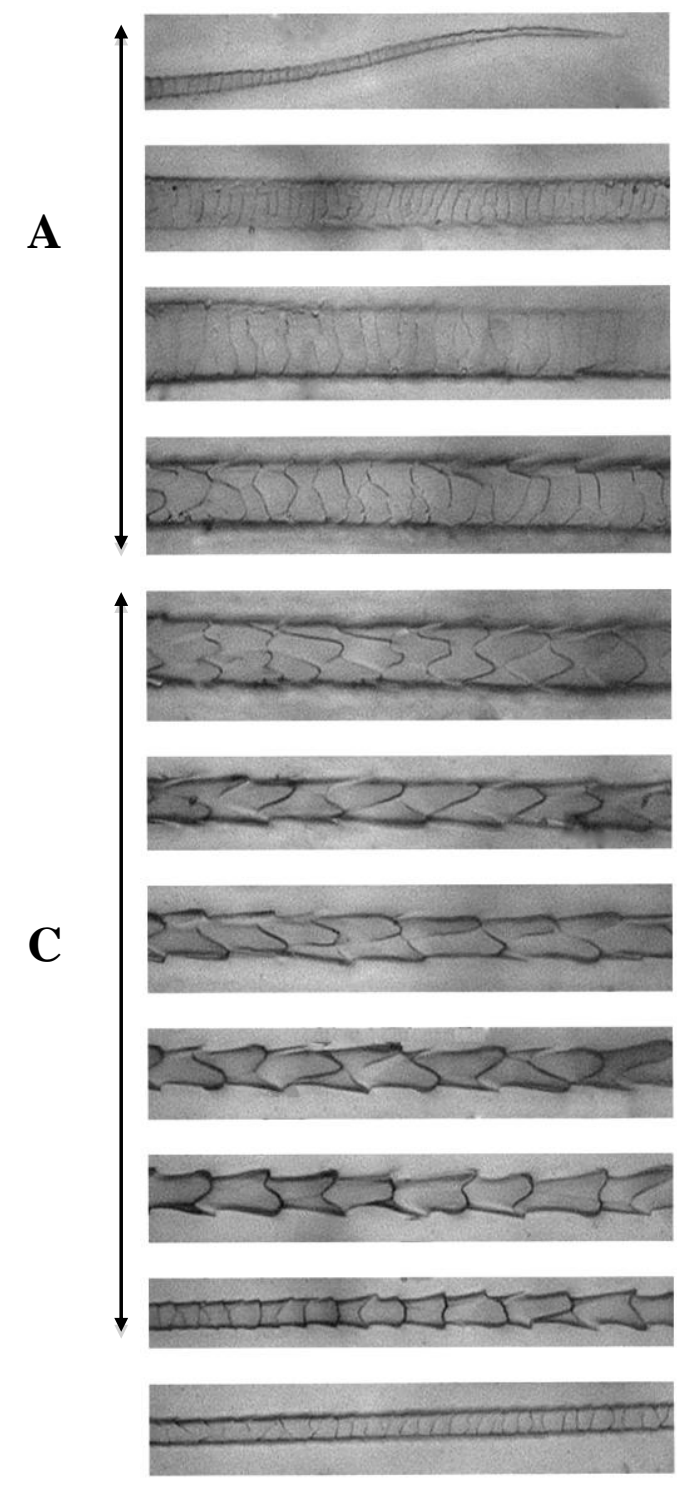

$\mathrm{GH} 2$

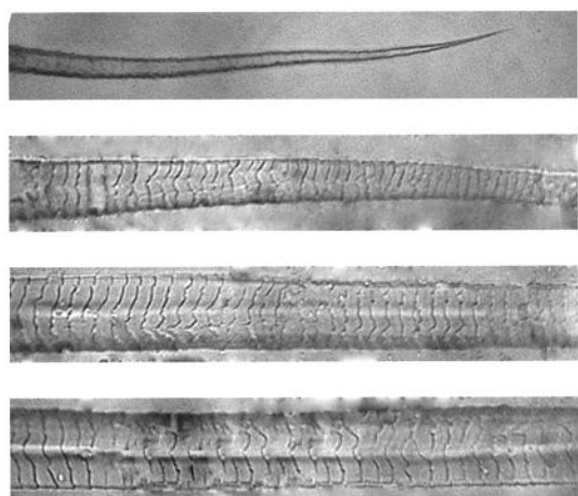

B
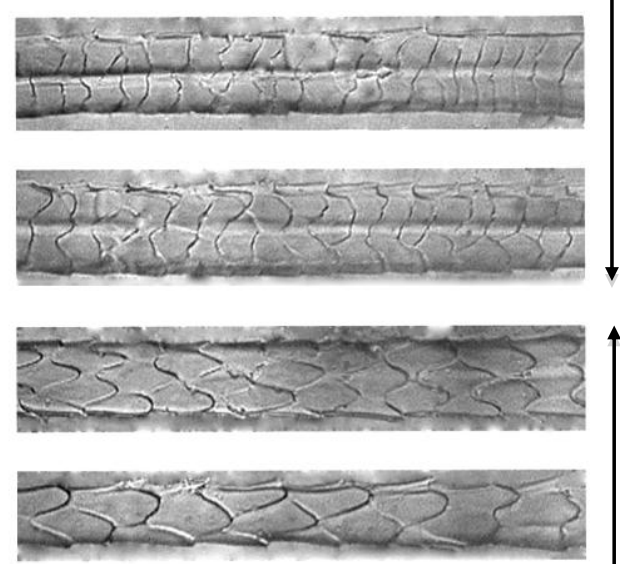

D
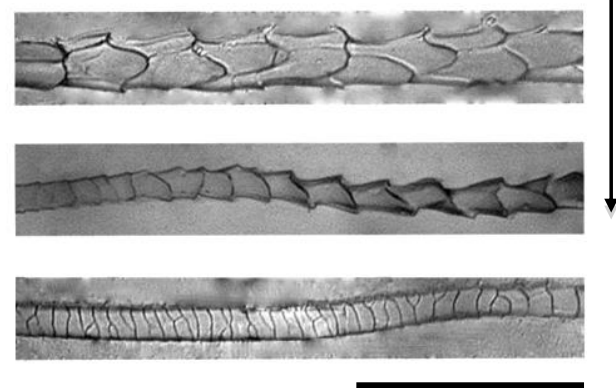

$0.1 \mathrm{~mm}$

A. GH1 - irregular wave (distant to near smooth)

B. $\mathrm{GH} 2$ - streaked (distant to near smooth)

C. GH1 - elongate petal (smooth)

D. GH2 - elongate to diamond shaped petal (smooth)

Figure 1i. Photomicrographs of cuticular scale patterns of GH1 and GH2 hairs of Suncus montanus. (Scales from tip to base of hairs - arranged from top to bottom) 
$\mathrm{GH} 1$

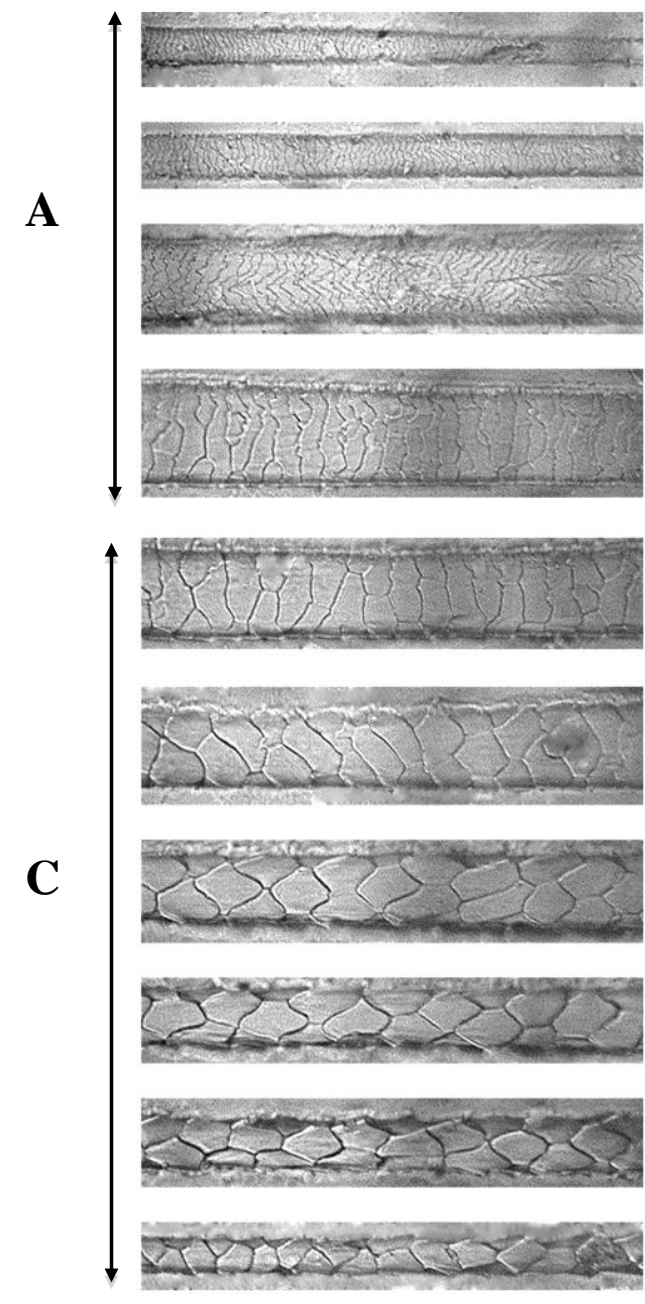

$\mathrm{GH} 2$
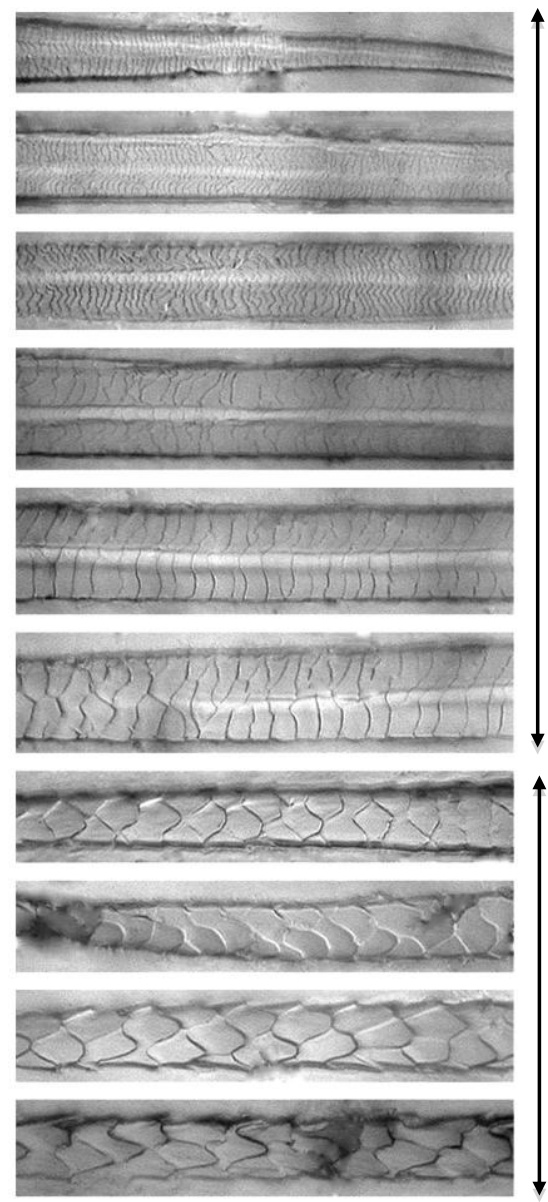

D

A. GH1 - irregular wave (close to near rippled)

B. GH2 - streaked (distant to near smooth to rippled)

C. GH1 - mosaic (distant smooth)

D. GH2 - elongate / broad petal (smooth)

Figure 1j. Photomicrographs of cuticular scale patterns of GH1 and GH2 hairs of Suncus murinus murinus. (Scales from tip to base of hairs - arranged from top to bottom) 
GH1

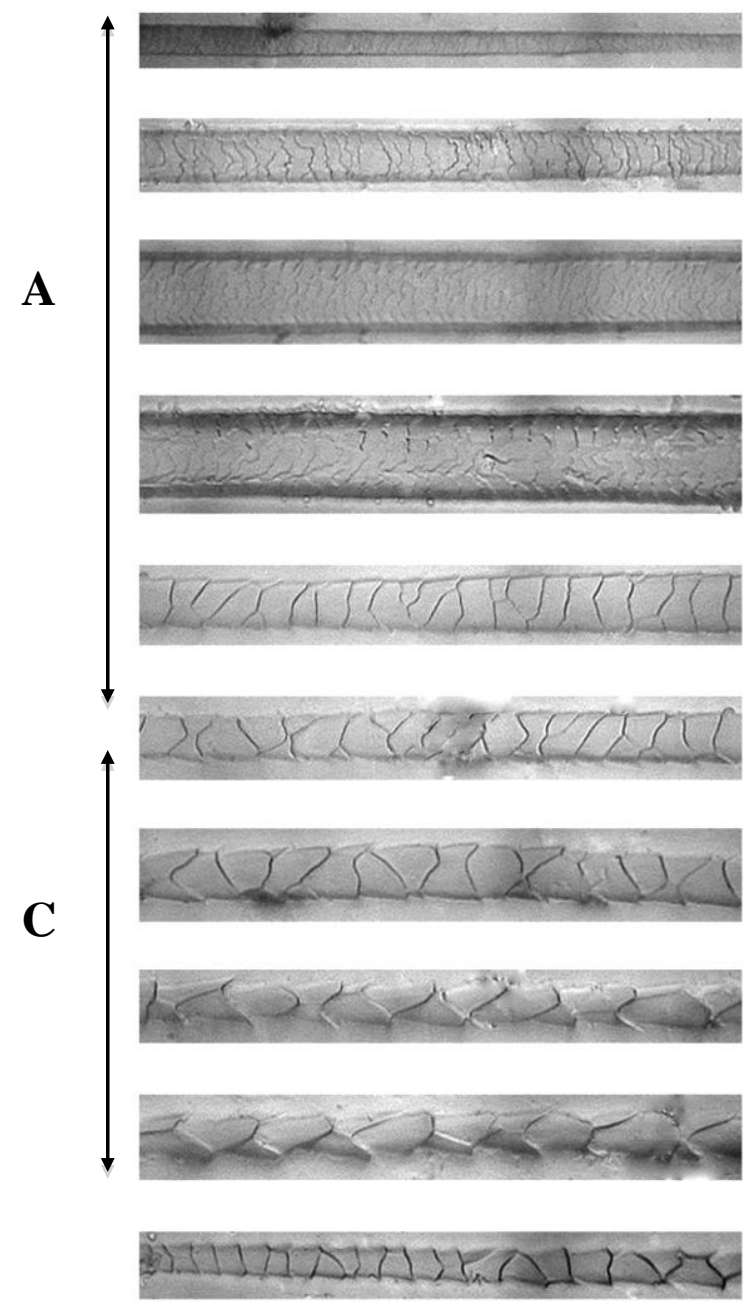

$\mathrm{GH} 2$

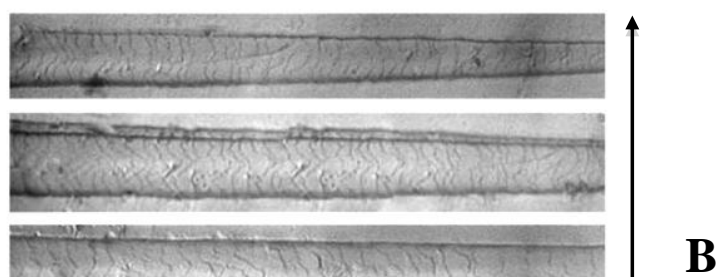

B
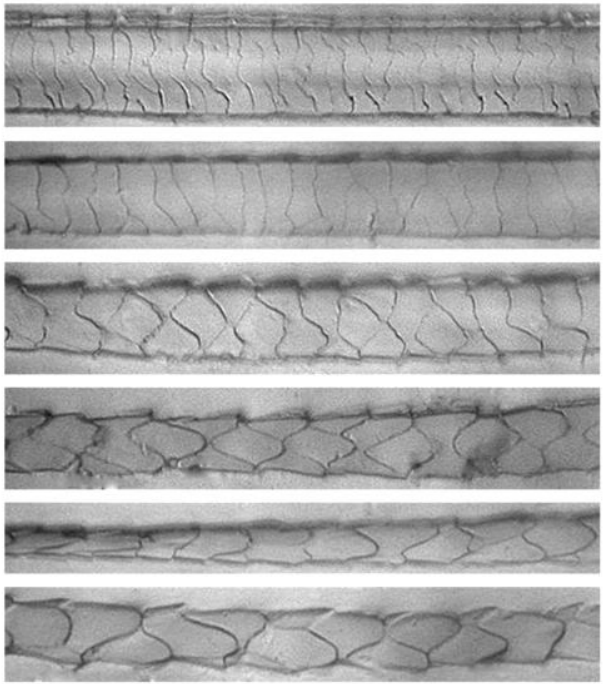

D

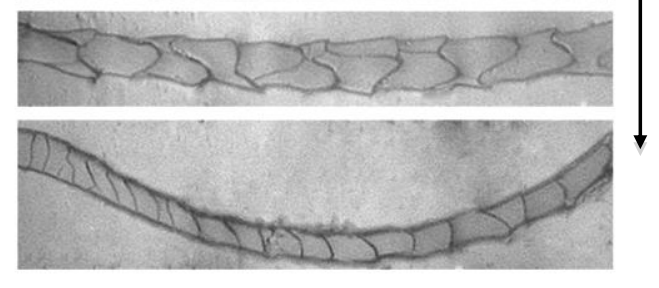

$0.1 \mathrm{~mm}$

A. GH1 - irregular wave (distant to close rippled)

B. GH2 - streaked (distant to near smooth to rippled)

C. GH1 - elongate to broad petal (smooth)

D. GH2 - elongate to diamond shaped petal (smooth)

Figure 1k. Photomicrographs of cuticular scale patterns of GH1 and GH2 hairs of Suncus murinus kandianus. (Scales from tip to base of hairs - arranged from top to bottom) 


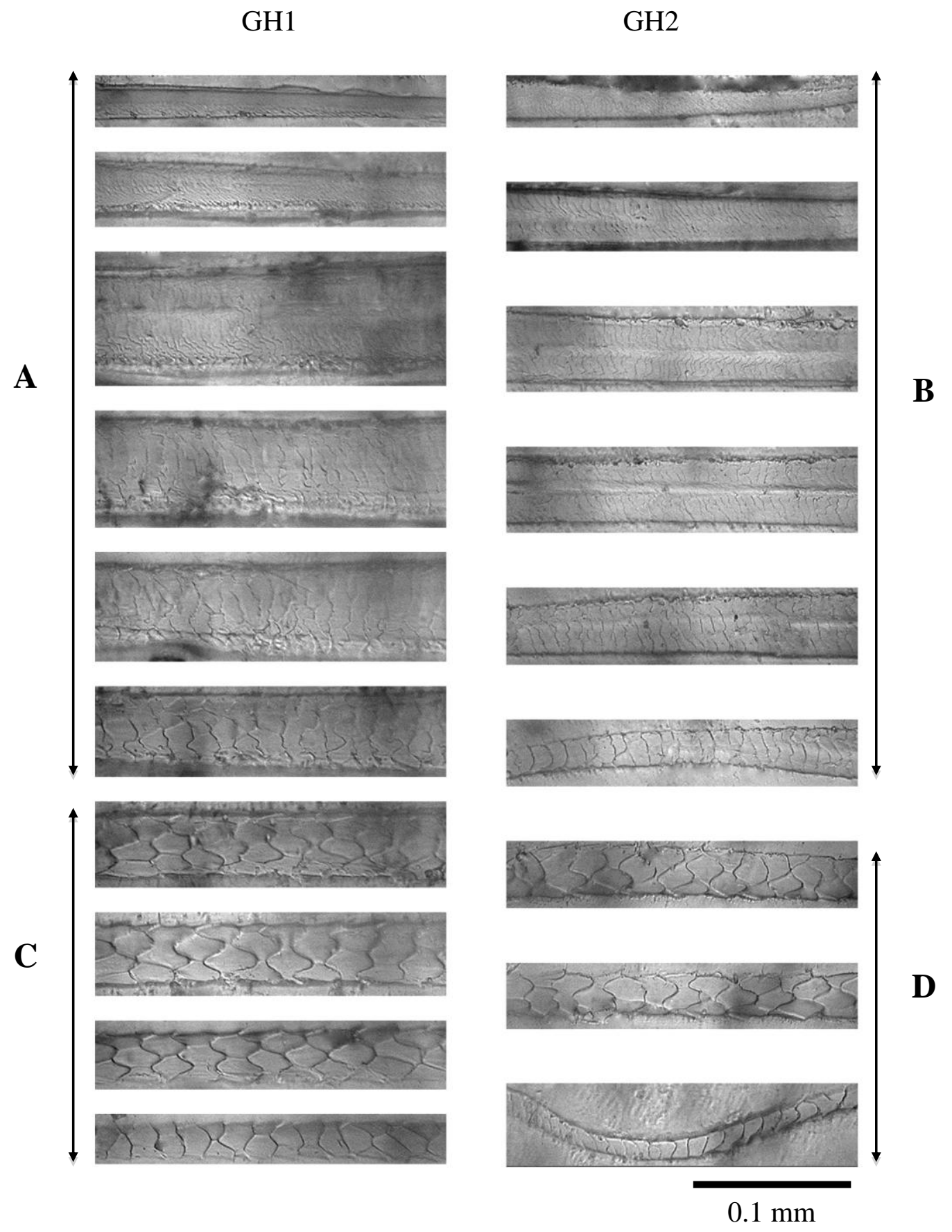
A. GH1 - irregular wave (close to near rippled)
B. GH2 - streaked (distant to near rippled)
C. GH1 - mosaic (distant smooth)
D. $\mathrm{GH} 2$ - elongate to broad petal (smooth)

Figure 11. Photomicrographs of cuticular scale patterns of GH1 and GH2 hairs of Suncus murinus caerulescens. (Scales from tip to base of hairs - arranged from top to bottom) 
Table 4. Length and maximal diameter of GH1 and GH2 hairs of species and subspecies of shrews in Sri Lanka. (Range, Mean with Standard deviation)

\begin{tabular}{|c|c|c|c|c|}
\hline \multirow{2}{*}{ Species } & \multicolumn{2}{|c|}{ GH1 } & \multicolumn{2}{|c|}{ GH2 } \\
\hline & Length (mm) & Diameter $(\mu \mathbf{m})$ & Length (mm) & Diameter $(\mu \mathbf{m})$ \\
\hline Solisorex pearsoni & $\begin{array}{l}10.8-13.9(11.4 \pm 1.4) \\
10.5-11.6(11.0 \pm 0.5)\end{array}$ & $\begin{array}{l}44.8-62.0(50.7 \pm 6.7) \\
58.8-70.9(65.4 \pm 5.0)\end{array}$ & $\begin{array}{l}5.7-10.2(8.1 \pm 2.0) \\
9.2-10.7(10.1 \pm 0.8)\end{array}$ & $\begin{array}{l}33.5-37.2(35.0 \pm 1.4) \\
52.9-63.1(60.0 \pm 4.4)\end{array}$ \\
\hline Feroculus feroculus & 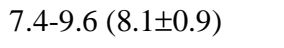 & $40.9-52.3(49.7 \pm 4.9)$ & $7.0-7.4(7.1 \pm 0.2)$ & $40.6-41.9(41.1 \pm 0.6)$ \\
\hline Crocidura miya & $\begin{array}{l}7.7-8.0(7.8 \pm 0.1) \\
7.2-8.1(7.7 \pm 0.3)\end{array}$ & $\begin{array}{l}36.4-41.1(39.9 \pm 1.9) \\
34.7-41.3(36.9 \pm 2.6)\end{array}$ & $\begin{array}{l}6.7-7.5(7.1 \pm 0.3) \\
6.4-6.7(6.6 \pm 0.1)\end{array}$ & $\begin{array}{l}30.1-42.2(37.7 \pm 4.8) \\
39.6-41.4(40.6 \pm 0.6)\end{array}$ \\
\hline C. hikmiya & $\begin{array}{l}6.0-7.5(6.6 \pm 0.7) \\
5.6-7.1(6.2 \pm 0.7)\end{array}$ & $\begin{array}{l}58.0-114.8(89.0 \pm 26.1) \\
59.0-84.8(72.5 \pm 10.7)\end{array}$ & $\begin{array}{l}6.0-7.2(6.6 \pm 0.4) \\
4.9-5.8(5.3 \pm 0.4)\end{array}$ & $\begin{array}{l}51.2-78.7(64.1 \pm 13.0) \\
78.8-104.8(91.5 \pm 9.5)\end{array}$ \\
\hline C. horsfieldii & $\begin{array}{l}4.0-5.1(4.6 \pm 0.4) \\
3.6-4.9(4.4 \pm 0.5)\end{array}$ & $\begin{array}{l}30.9-39.0(35.5 \pm 4.0) \\
26.7-30.6(28.3 \pm 1.8)\end{array}$ & $\begin{array}{l}4.4-4.5(4.5 \pm 0.0) \\
4.0-4.4(4.1 \pm 0.2)\end{array}$ & $\begin{array}{l}25.1-41.8(33.2 \pm 6.3) \\
22.3-28.4(24.8 \pm 2.4)\end{array}$ \\
\hline Suncus zeylanicus & $5.4-7.3(6.6 \pm 0.8)$ & $38.1-44.9(42.5 \pm 2.9)$ & $6.6-6.9(6.8 \pm 0.1)$ & $22.5-35.8(27.1 \pm 5.2)$ \\
\hline S. fellowesgordoni & $3.1-3.6(3.3 \pm 0.2)$ & $44.6-50.0(47.8 \pm 2.1)$ & $3.2-3.3(3.2 \pm 0.0)$ & $46.0-54.2(50.2 \pm 3.0)$ \\
\hline S. etruscus & $1.0-1.2(1.1 \pm 0.1)$ & $18.2-25.3(20.8 \pm 2.8)$ & $0.9-1.0(0.9 \pm 0.0)$ & $22.4-25.5(24.0 \pm 1.3)$ \\
\hline S. montanus & $\begin{array}{l}7.2-8.0(7.5 \pm 0.3) \\
7.8-9.5(8.4 \pm 0.6)\end{array}$ & $\begin{array}{l}28.2-34.8(31.2 \pm 2.8) \\
36.5-38.2(37.4 \pm 0.7)\end{array}$ & $\begin{array}{l}6.5-6.6(6.6 \pm 0.1) \\
7.6-7.9(7.8 \pm 0.1)\end{array}$ & $\begin{array}{l}26.1-26.5(26.3 \pm 0.1) \\
29.2-34.0(31.9 \pm 1.8)\end{array}$ \\
\hline S. murinus murinus & $\begin{array}{l}5.5-7.3(6.1 \pm 0.7) \\
6.2-8.4(7.4 \pm 0.8)\end{array}$ & $\begin{array}{l}44.9-50.2(48.1 \pm 2.5) \\
56.1-61.3(58.5 \pm 2.2)\end{array}$ & $\begin{array}{l}5.0-5.3(5.2 \pm 0.2) \\
5.7-6.3(6.1 \pm 0.2)\end{array}$ & $\begin{array}{l}33.7-45.1(38.6 \pm 4.5) \\
42.9-49.4(46.9 \pm 2.4)\end{array}$ \\
\hline S. m. kandianus & 7.0-7.4 (7.1 \pm 0.2$)$ & $33.5-42.5(37.8 \pm 4.1)$ & $5.3-6.2(5.6 \pm 0.3)$ & $31.9-39.9(35.5 \pm 3.1)$ \\
\hline S. m. caerulescens & $6.9-8.2(7.5 \pm 0.5)$ & $44.3-51.3(48.6 \pm 2.9)$ & $6.1-6.5(6.4 \pm 0.2)$ & $44.6-51.7(47.2 \pm 2.9)$ \\
\hline
\end{tabular}




\section{Key to the shrew species of Sri Lanka using hair anatomy}

(Should be used in conjunction with photomicrographs of cuticular scale patterns and medulla, and illustrations of cross-sections of hair given in Figs. 1 and 2, Table 2)

1. a. Cross-sections of $\mathrm{GH} 2$ with no emarginations .2

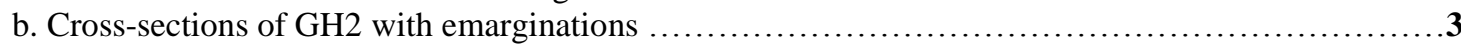

2. a. Cross-sections of GH2 circular or oval with one flat/ concave side Solisorex pearsoni

b. Cross-sections of $\mathrm{GH} 2$ square shaped Suncus zeylanicus

3. a. Cross-sections of GH2 with 2 deep emarginations Feroculus feroculus

b. Cross-sections of $\mathrm{GH} 2$ with 4 deep or shallow emarginations 4

4. a. Cross-sections of $\mathrm{GH} 2$ with 4 deep emarginations .5

b. Cross-sections of GH2 with 2-4 shallow emarginations .6

5. a. X-shaped cross-sections in the shield of $\mathrm{GH} 2$ hairs; medulla single circular or oval shaped in cross-sections of $\mathrm{GH} 2$ hairs Crocidura miya

b. Butterfly wings shaped cross-sections in the shaft of GH2 hairs; medulla broken into two, teardrop-shaped in cross-sections of $\mathrm{GH} 2$ hairs.

6. a. Guard hair less than $2 \mathrm{~mm}$ long. Suncus etruscus

b. Guard hair more than $3 \mathrm{~mm}$ long 7

7. a. Four petal-shaped cross sections in the shield of $\mathrm{GH} 2$ hairs Crocidura horsfieldii

b. Cross-section shapes different from above 8

8. a. Cross-sections in the shield of $\mathrm{GH} 2$ hairs with two deep and two shallow emarginations giving the appearance of an ' $\mathrm{H}$ '

b. Cross-section shapes of $\mathrm{GH} 2$ hairs different from above

9. a. GH1 hairs have mosaic scales in the shaft. .10

b. GH1 hairs have elongate petals in the shaft... .11

10. a. Regular ladder pattern medulla, occasionally irregular. Suncus m. murinus b. Highly irregular ladder pattern medulla Suncus m. caerulescens

11. a. Scales in the shield of GH1hairs are comparatively less rippled than below. Suncus montanus

b. Scales in the shield of GH1 hairs are comparatively more rippled .Suncus m. kandianus 


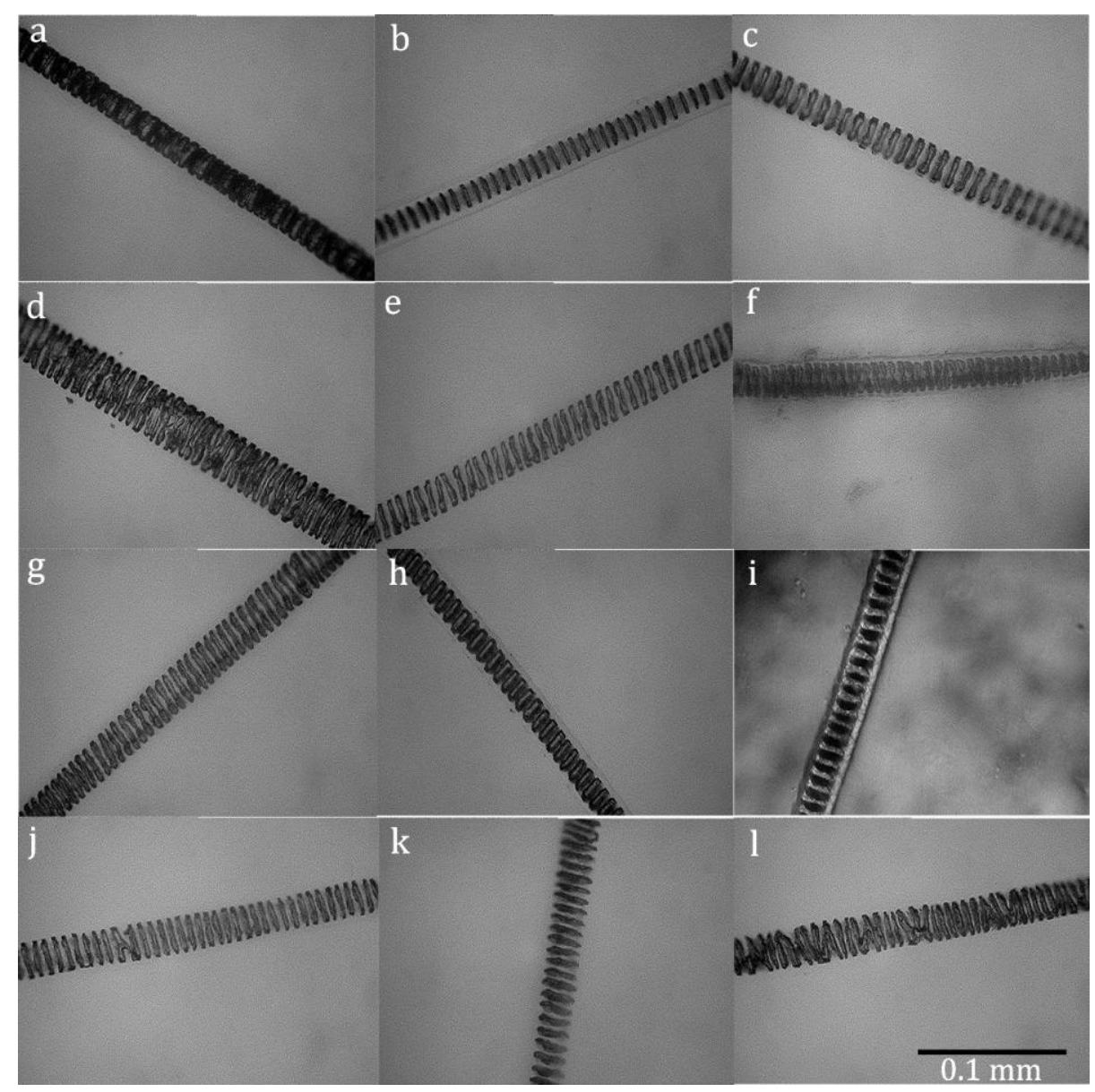

Figure 2. Medulla patterns in GH2 hairs of shrews; (a) Solisorex pearsoni; (b) Feroculus feroculus; (c) Crocidura miya; (d) C. hikmiya; (e) C. horsfieldii; (f) Suncus etruscus; (g) S. fellowesgordoni; (h) S. zeylanicus; (i) S. montanus; (j) S. murinus murinus; (k) S. m. kandianus and (l) S. m. caerulescens.

\section{DISCUSSION}

The dorsal guard hairs of the shrew species examined exhibited morphological and morphometric characters that facilitate their identification. Seven species, Solisorex perasoni, Feroculus feroculus, Crocidira miya, $C$. hikmiya, C. horsfieldii, Suncus zeylanicus and $S$. fellowesgordoni can be distinguished using cross-sections of $\mathrm{GH} 2$ hairs alone. This is a special situation where many of the species can be identified using only cross-sections of hairs. Cross-sections of hairs alone are reported to be important in diagnosing species (Dagnall et al., 1995), but most often they are useful in combination with other characters (Teerink, 1991).

Cuticular scale patterns are also characteristic to species and subspecies and can be used in their identification. Shields of all GH1 and GH2 hair have waved or streaked scale patterns while the scale pattern in the shaft varies more among the species. All species studied here have more than one type of scale pattern along the length of the hair, as reported also in other studies (e.g., Cavia, 2008; Teerink, 1991). Most studies report the pattern in the medial part of the shaft, since they vary between species and are more reliable in their identification (Amerasinghe, 1993; Chehébar and Martìn, 1989; Fernández and Rossi, 1998; Meyer et al., 2002). We report the scale patterns through the whole length of the hairs as we observed that scale pattern in the shield in combination with other features are also helpful in distinguishing species. Cuticular scales alone are used by many authors to identify species (Stefen, 2011), but for many species cuticular scales are of limited taxonomic value and unreliable by themselves for identification (Williams, 1938; Nason, 1948). Though it is possible to identify the shrews of Sri Lanka using scale patterns of guard hairs alone, it is advisable to consider other features before 
making conclusions, especially cross-sections, since they are characteristic to species.

The medullae appear to be of least importance in shrew species identification. All shrews have unicellular ladder medullar patterns (Williams, 1938; Teerink, 1991). However, two species, C. hikmiya and $S$. murinus caerulescens, in this study have distinct irregular ladder patterns opposed to the regular ladder pattern in others. The appearance of the medulla ladder pattern can also be helpful in distinguishing species such as S. etruscus (Fig. 2f). Hence, the medulla pattern can be used in distinguishing species in combination with other features.

Hair profile or the types of hair present in species can also be an important character in distinguishing species (Williams, 1938; Teerink, 1991). However, the hair types and shapes of hairs studied here did not show variation that warrant reporting.

The variations in cross-sections, cuticuar scales and medulla within a species or among hairs of an individual, are important to consider when distinguishing species using hair anatomy. We noted that there was no distinguishable variation within species or among hairs of an individual in cross-sections and medulla patterns. However, for several species only a single specimen was available, hence this may not be conclusive. But, illustrations of crosssections given for few species in Amerasinghe (1993) also correspond to what we report here. Cuticlur patterns on the other hand varied within a species and among hairs of the same individual to some extent. Nevertheless, they had the same basic pattern and could be identified as belonging to a single species. Due to the variation in cuticular scale pattern, they are not regarded as a reliable diagnostic feature by some authors.

When making scale casts we did not make any effort to take the scale patterns of a specific side of the hair as it is difficult to determine the side of the hair that falls on the slide. Hence, the thickness of the scale casts cannot be compared with the maximal diameter, as it depends on the side the hair falls on the slide. However, all the cuticular patterns that we looked at for each species had similar patterns though the thickness of the hair varied to some extent.

The identity of Suncus zeylanicus was questioned by Meegaskumbura et al. (2010), as the skull of the type specimen did not show a marked difference from $S$. montanus. However, hairs of $S$. zeylanicus is clearly distinguishable from other species by its characteristic hair cross-sections and cuticular scales.
The method applied here, apart from its use in taxonomic studies, has direct applications in conservation efforts for shrews. Hair morphology is especially useful in taxonomy, identification of prey in predator faeces and monitoring mammal fauna by means of hair-tube surveys.

\section{ACKNOWLEDGEMENTS}

We are grateful to Paula Jenkins of Natural History Museum (NHM), London, for providing a hair sample from Suncus zeylanicus. and Krishan Ariyasiri for assisting with laboratory work. We also thank Rohan Pethiyagoda for his valuable comments that helped improve the manuscript.

\section{REFERENCES}

Amerasinghe F.P. (1983). The structure and identification of the hairs of the mammals of Sri Lanka. Ceylon journal of Science (Biological Sciences) 16(1\&2):76-125.

Amerasinghe F.P. and Ekanayake, U.B. (1990). Food habits of the Leapard (Panthera pardus fusca) in Sri Lanka. Ceylon journal of Science (Biological Sciences) 21(1):17-24.

Backwell L., Pickering R., Brothwell D., Berger, D., Witcomb M., Martill D., Penkman K. and Wilson A. (2009). Probable human hair found in a fossil hyaena coprolite from Gladysvale cave. South Africa Journal of Archeological Science 36(6): 1269-1276.

Birngruber, C., Ramsthaler, F. and Verhoff M.A. (2009). The color(s) of human hairForensic hair analysis with SpectraCube ${ }^{\circledR}$. Forensic Science International 185(1-3): 1923.

Brazej, A., Galatik, A., Galatik, J. Krul, Z. and Mladek, M. (1989). Atlas of Microscopic Structures of Fur Skins 1. Elsvier. Amsterdam.

Broeck, W.V., Mortier, P. and Simoens, P. (2000). Scanning electron microscopic study of different hair types in various breeds of rabbits. Folia morphol 60(1):33-40.

Brunner, H. and Coman, B. (1974). The Identification of Mammalian Hair. Inkata Press. Melbourne.

Cavia, R., Andrade, A., Zamero, M.E., Ferna'ndez, M.S., Muschetto, E., Cueto G.R. and Sua'rez O. V. (2008). Hair structure of small rodents from central Argentina: A tool for species identification. Mammalia 72: 3543. 
Chehébar C. and Martı'n S. (1989). A guide to the microscopic identification of hairs from patagonian mammals. Donana Acta Vertebrata 16: 247-291.

Dagnall, J. L., Duckett, J. G. and Gurnell J. (1995). A simple negative staining technique for the identification of mammal hairs. Journal of Zoology 237(4): 670-675.

Day, M.G. (1966). Identification of hair and feather remains in the gut and faeces of stoats and weasels. Journal of Zoology (London) 148: 201-217.

Fernández, G.J. and Rossi, S.M. (1998). Medullar type and cuticular scale patterns of hairs of rodents and small marsupials from the Monte Scrubland (San Luis Province, Argentina). Mastozoologia Neotropical 5(2):109-116.

Hauseman L.A. (1920). Structural Characteristics of the Hair of Mammals. The American Naturalist 54(635): 496-523.

Hausman, L. A., (1934). Histological Variability of Human Hair, American Journal of Physical Anthropology 18: 415-429.

Kondo, K. (2000). The diversity of Mammalian pelage. Journal of Faculty of Agriculture. Hokkaido University 70(1): 9-17.

Marinis A.M. and Asprea A. (2006a). Hair identification key of wild and domestic ungulates from southern Europe. Wildlife Biology 12: 305-320.

Marinis. A.M. and Asprea, A. (2006b). How did domestication change the hair morphology in sheep and goats?. Human evolution 21(2):139-149.

Mayer, W.V. (1952). The hair of California mammals with keys to the dorsal guard hairs of California mammals. Am. midl. nat. 48(2):480-512.

Meegaskumbura, S., M. Meegaskumbura and C. J. Schneider (2010). Systematic relationships and taxonomy of Suncus montanus and $S$. murinus from Sri Lanka. Molecular Phylogenetics and Evolution, 55: 473-487.

Meegaskumbura, S., M. Meegaskumbura and C. J. Schneider (2012). Re-evaluation of the taxonomy of the Sri Lankan pigmy shrew Suncus fellowesgordoni (Soricidae: Crocidurinae) and its phylogenetic relationship with $S$. etruscus. Zootaxa 3187: 57-68.

Meegaskumbura, S. and Schneider, C.J., (2008). A taxonomic evaluation of the shrew Suncus montanus (Soricidae: Crocidurinae) of Sri Lanka and India. Ceylon Journal of Science 37(2): 129-136.
Meegaskumbura, S., Meegaskumbura, M. Pethiyagoda, R., Manamendra-Arachchi, K. and Schneider, C. J. (2007). Crocidura hikmiya, a new shrew (Mammalia: Soricomorpha: Soricidae) from Sri Lanka. Zootaxa 1665: 19-30.

Meyer, W., Hu $\square$ lmann, G. and Seger, H. (2002): SEM-Atlas on the Hair Cuticle Structure of Central European mammals. Verlag M. and S. Schaper Alfred, Hannover.

Meyer, W., Schnapper, A., Hulmann, G. and Seger, H. (2000). Domestication-related variations of the hair cuticula pattern in mammals. Journal of animal breeding and genetics 117(4): 281-283.

Nason E. S. (1948). Morphology of Hair of Eastern North American Bats. American Naturalist 39(2): 345-361.

Perrin, M.R. and Campbell, B.S. (1980). Key to the mammals of the Andries Vosloo Kudu Reserve (Eastern Cape), based on their hair morphology, for the use in predator scat analysis. South African Journal of Wildlife Researc. 10: 1-14.

Phillips, W.W.A. (1980). A manual of the mammals of Sri Lanka. Wildlife and Nature Protection Society of Sri Lanka, Colombo.

Rosen, S. I. (1974). Identification of Primate hair. Journal of Forensic Science 19(1): 109112.

Short H. L. (1978). Analysis of Cuticular Scales on Hairs Using the Scanning Electron Microscope. Journal of Mammalogy 59(2): 261-268.

Spaulding, R., Krausman P. R. and Ballard W. B. (2000). Observer Bias and Analysis of Gray Wolf Diets from Scats. Wildlife Society Bulletin 28(4): 947-950.

Stefen, C. (2011). On the hair cuticle structure of the rodent Laonastes aenigmamus (Mammalia: Rodentia: Diatomyidae). Vertebrate Zoology 61(3): 373-376.

Teerink, B.J. (1991). Hair of West-European mammals: atlas and identification key. Cambridge University Press, Cambridge.

Vullo R., Girard V., Azar D. and Néraudeau D. (2010) Mammalian hairs in Early Cretaceous amber. Naturwissenschaften 97(7): 683-687.

Wildman, A.B. (1954). The microscopy of animal textile fibers. Wool research association Leeds.

Williams, C. (1938). Aids to the Identification of Mole and Shrew Hairs with General Comments on Hair Structure and Hair Determination. The Journal of Wildlife Management 2(4): 239-250. 